\title{
ZOONOSES FROM PETS HORSES, DONKEYS AND MULES: WITH SPECIAL REFERENCES TO EGYPT
}

\author{
By \\ AYMAN T. A. MORSY ${ }^{1}$, MOSTAFA S. M. SALEH ${ }^{2}$ \\ AND TOSSON A. MORSY ${ }^{3}$
}

Consultant of Tropical Medicine, The Ministry of Interior Hospitals ${ }^{1}$, Cairo, Consultant of Parasitology, Military Medical Academy and Department of Parasitology, Faculty of Medicine, Ain Shams University, Cairo $11566^{3}$, Egypt

\begin{abstract}
A zoonosis is an animal disease that is transmissible to humans. Humans are usually an accidental host that acquires disease through close contact with an infected animal, who may or may not be symptomatic. Children are at highest risk for infection because they are more likely to have close contact with pets. Pets are responsible for transmission of an extensive array of bacterial, fungal, and parasitic zoonotic pathogens. The route of transmission can be through the saliva (e.g., bites or contaminated scratches), feces, respiratory secretions, direct contact, or by the animal acting as a vehicle and source of tick or flea exposure. Although pets have been implicated in transmission of zoonoses to their owners, risk of transmission from contact with pets is low and may be further reduced by simple precautions.
\end{abstract}

Key words: Zoonoses, Pets Horses, Donkeys and Mules.

\section{Introduction}

Pets serve valuable social roles in society (Parslow and Jorm, 2003). Pets may lower blood pressure, reduce cholesterol and triglyceride levels, and improve feelings of loneliness, while increasing opportunities for exercise, outdoor activities, and socialization, the pet-therapy programs are desirable components of the multidisciplinary treatment for frail elderly patients in long-term care (Stasi et al, 2004).

Despite these benefits, pets present zoonotic risks, especially for the immunocompromised hosts (Pickering et al, 2008). In addition, to infection from pets, there have been multiple outbreaks of enteric disease associated with animal exposure in public settings, such as county fairs, farms, and petting zoos (Sabry et al, 2012). In a review of 55 such outbreaks, most were due to Escherichia coli O157; 58\% and Salmonella species; 22\% (Steinmuller et al, 2006). The epidemiology of zoonoses from pet dogs and cats tops allpet animals worldwide (Sabry et al, 2012, 2013).
Definition: A zoonosis is an animal disease that is transmissible to humans. Humans are usually an accidental host that acquires disease through close contact with an infected animal, who may or may not be symptomatic. Incidence: The American Veterinary Medical Association's 2005 to 2006 survey of United States pet owners found that $63 \%$ of all United States households have at least one pet (www.avma.org). The most common route of infection related to pet contact, is through bites, especially in children (Myers et al, 2012). To the present authors knowledge, in Egypt, and other Arab countries non surveyed pet owners and consequently their zoonoses.

Risk Factors: Clinicians should ask about pets when taking a medical history and formu-lating a differential diagnosis. Many of the risks posed by pet ownership can be reduced by good hygiene after handling pets, careful pet selection, and proper pet care . New pets can pose more of a health risk. Adult pets are generally safer than younger animals, since they are less likely to be involved in playful activities that include 
scratching and biting (Juckett, 1997). Children are at highest risk for infection because they are more likely to have close contact with pets.

Transmission: Transmission of an extensive array of bacterial, viral, and parasitic zoonotic pathogens can occur from pets. Many different routes of transmission can cause infections related to pets including: Infectious saliva that contaminate bite wounds, skin abrasions, or mucous membranes Hand-to-mouth transfer of microorganisms, cysts, or oocysts (eggs) from feces of an infected animal Insect bites when these vectors are carried into the home by pets or when bites transmit disease from a pet, acting as a disease reservoir, to humans Aerosol from body fluids (e.g., respiratory secretions, placenta) Scratches Contamination of water or the environment with pathogen containing animal urine Contamination of an object that is subsequently put into the mouth as pacifier (Weese et al, 2007).

Fecal transmission: Common zoonotic pathogens causing equine gastroenteritis include Salmonella, Campylobacter, Vibrio, Cryptosporidium and Giardia. Although the horses are not the usual source for human gastrointestinal infection, these pathogens should be considered in a patient who presents with compatible symptoms who has had contact with a horse with diarrhea (Roug et al, 2013).

Salmonella: An outbreak of salmonellosis in a population of hospitalized horses resulted in the closure of a veterinary teaching hospital for a period of 10 weeks (Ward et $a l, 2005)$. Fecal samples were collected from suspected cases and cultured for Salmonella. Thirty-three cases of infection by a multidrug-resistant strain of $S$. typhimurium were detected. S. typhimurium might have been introduced into the hospital environment by a foal presenting with diarrhea. Nyberg et al. (2011) reported that Salmonella typhimurium and Enterococcus faecalis were successfully treated by application of hydrated lime $(\mathrm{Ca}(\mathrm{OH})(2))$. Salmonella spp. infections transmitted to humans usually result in a mild, self-limited gastroenteritis. However, severe invasive illness, such as septicemia or meningitis, can occur especially in infants and immunocompromised persons (Delaloye et al, 2004). In Egypt, Ahmed and Shimamoto (2014) stated that foodborne pathogens are a major threat to food safety, especially in developing countries where hygiene and sanitation facilities are often poor. Salmonella enterica, Escherichia coli $\mathrm{O} 157: \mathrm{H} 7$ and Shigella spp. were among the major causes of outbreaks of foodborne diseases

Campylobacter: Campylobacter enteritis in humans presents after an incubation period of one to seven days as a syndrome most commonly characterized by prominent abdominal pain and profuse diarrhea that is often bloody (Brzank and Wollenhaupt, 2013). Said et al. (2010) in Egypt stated that Campylobacter spp. are the major cause of enteritis in humans and more than $90 \%$ of reported infections are caused by $C$. jejuni. The main mechanism for resistance to fluoroquinolones is an alteration in the gyrA QRDR. MAMA PCR provides an economical and rapid means for screening fluoroquinolone resistance. Besides, Badawy et al. (2012) found that Campylobacter spp. was usually associated with Giardia spp.

Cryptosporidium: Cryptosporidium is an intracellular protozoan parasite that is associated with gastrointestinal diseases in all classes of vertebrates including horses. The cryptosporidial oocyst shedding is primarily found in immunocompromised or immature horses and rarely from healthy mature horses (McKenzie and Diffay, 2000). Cryptosporidium infection in immunocompetent individuals has a variable presentation, it can be asymptomatic, cause a self-limited gastroenteritis (usually resolving in 10 to 14 days without treatment), or can cause more severe diarrhea (Aho, 1983). In immunocompromised hosts, the illness was more frequently protracted and severe, and can lead to significant malabsorption and weight loss. Cryptosporidium parvum and C. homi- 
nis are the usual pathogens in humans; immunocom-promised hosts can also be infected by other Cryptosporidium spp. (Abdou et $a l, 2013)$. In Egypt, so many authors dealt with zoonotic cryptosporidiosis (Youssef et al, 2008). Mousa et al. (2010) stated Cryptosporidiosis, a parasitic zoonosis, while typically a short-term infection, has a global distribution and can cause severe illness in children and other vulnerable populations and they found that artificial breast feeding was not evaluated as only 3 infants had $C$. parvum compared to non-parasitic cause in 1 on the breast feeding.

Giardia lamblia: G. lamblia (also known as $G$. duodenalis or G. intestinalis) is a flagellated protozoan parasite and one of the most common gastrointestinal parasites in the United States. There is evidence supporting the zoonotic transmission of Giardia; horses may constitute a potential source for human infection of Giardia either directly or via contamination of watersheds (Traub et al, 2005).

The spectrum of clinical disease in humans includes asymptomatic infection, selflimited acute giardiasis, and chronic infection. G. lamblia causes both epidemic and sporadic disease and is an important etiology of water-borne and food-borne diarrhea, day-care center outbreaks, and diarrhea in international travelers and adoptees (Cacciò and Pozio, 2001). There are different strains of G. lamblia and antigenic variations within single isolates, but the significance of this heterogeneity for pathogenicity and the development of immunity is unclear (Musher and Musher, 2004). The pathogenesis of the diarrhea and malabsorption that can occur in giardiasis is incompletely understood since Giardia is not invasive organisms. The major structural and functional abnormalities associated with giardiasis are found in the small intestine. Human infection may be associated with a spectrum of light microscopic changes that range from no abnormalities, to mild or moderate partial villous atrophy, to subtotal villous atrophy in severe cases.
An increase in crypt depth may also be seen. Even in the absence of changes in villous and crypt architecture, shortening and disruption of microvilli may occur. In addition, deficiencies in epithelial brush border enzymes (e.g., lactase) can develop. These alterations in epithelial structure and function probably play a role in pathogenesis (Dizdar et al, 2010). Moreover, Olson et al. (1997) reported double infection with giardiasis and cryptosporidiosis in Canadian farm animals

In Egypt many authors reported giardiasis in man and animals, Risk et al. (2004) studied the Genotyping of human giardiasis in relation to anti-Giardia secretory $\operatorname{IgA}$ and mucosal histo-pathology. Shatla et al. (2004) in Cairo detected G. lamblia antibodies in saliva of hospitalized children. Mahmoud et al. (2004) reported that giardiasis was one of the etiologic agent of skin dermatitis. Abou Holw et al. (2009) reported that giardiasis is one of the most common enteroprotozoal diseases; its association with Helicobacter pylori is a common clinical finding and that endoscopic and histopathologic examination showed significant gastric lesions in this group of patients as compared to those suffering only $G$. lamblia. El-Mohammady et al. (2012) stated that acute diarrhea continues to be a major cause of morbidity and mortality in children from developing countries and that Adenovirus, astrovirus, norovirus and $G$. lamblia were detected as the sole pathogen in $2 \%(n=34), 3 \%(n=56), 9 \%$ $(n=191)$ and $7 \%(n=146)$ of the cases, respectively. They concluded that the incorporation of immunoassays yielded useful data in identifying pathogens in previously pathogen-negative diarrhea cases.

Clostridium difficile: $C$. difficile infection occurs in foals and horses following treatment with antibiotics and outbreaks might occur in veterinary hospitals (Madewell et al, 1995). Clostridium difficile is the most frequent cause of nosocomial diarrhea, and a significant cause of morbidity and mortality among hospitalized patients (McDonald, 2005). The vaccination with a partially puri- 
fied preparation of inactivated toxins $\mathrm{A}$ and $\mathrm{B}$ may be a viable strategy for active immunization (Kotloff et al, 2001). Both the incidence and severity of $C$. difficileassociated diarrhea (CDAD) are increasing and that inpatient health care facilities are the primary site of $C$. difficile transmission. There are substantial short- and long-term attributable costs associated with $C$. difficile (Dubberke et al, 2008). The prevention and control of $\mathrm{C}$. difficile requires a variety of interventions (Muto et al, 2007). To prevent spread to household contacts, patients with C. difficile should wash hands frequently with soap and water, especially after using the bathroom and before food preparation. Patients with diarrhea should avoid using the same toilet as other family members (Warny et al, 1994). In the hospital environmental cleaning is a must because the spores of $C$. difficile can survive on dry surfaces for up to several months, environmental cleaning in the setting of patient care for CDAD requires special attention (CDC, 2007).

In Egypt, Ibrahim (2014) gave an illustrative review on the prevention and control of CDAD in healthcare settings requires careful attention to hand hygiene, contact precautions, and environmental cleaning. Antibiotic restriction can reduce the $C$. difficile rates; strategies for antibiotic use should be tailored to health care delivery in particular institutions. There is insufficient data for routine use of probiotics, treatment of asymptomatic carriers, or vaccination

Aerosol transmission: Many microorganisms are aerosol zoonoses from the equines.

Rhodococcus equi: $R$. equi is a gram-positive pleomorphic organism that appears coccoid on solid media but forms long rods or short filaments in liquid media. The organisms can be acid fast with the Ziehl-Neelsen stain (Giguère et al, 2011).

$R$. equi is a soil organism carried in the gut of many herbivores and widespread in their environment. On horse farms, progressive environmental contamination with $\mathrm{R}$. equi has been related to the length of time that animals were present. The highest numbers of organisms have been found in the surface soil on horse farms with endemic disease. Exposure to soil contaminated with herbivore manure is likely the major route of acquisition for both animal and human infection (Rosen and Jablon, 2003). Most human infections have been associated with immune system dysfunction (e.g., HIV, solid organ transplant recipients). Pulmonary infections are the most common form of human disease (Mulè et al, 2012). Besides, Nath et al. (2013) reported of $R$. equi granulomatous mastitis immunocompetent woman. Bildik et al. (2013) reported two cases of Rhodococcus equi bacteremia as a cause of sepsis in premature infants who had increasing respiratory distress with multiple episodes of apnea

In Egypt: Mohamed et al. (2009) reported suspected lesions in $110 / 745$ (14.8\%) of the slaughtered pigs' carcasses, from which only 67 specimens produced suspected mycobacterial colonies. Sequence analysis of IGS resolved the identities of 10 of the 11 conventionally unidentified isolates as being 4 different non-tuberculous Mycobacterium species. The last isolate was proposed as a non-Mycobacterium species and was confirmed by its identification as Rhodococcus equi based on the 16S ribosomal DNA sequence analysis.

Brucella: Brucella spp. infection in horses appears to have a worldwide distribution, but human infections transmitted by horses are uncommon. The Brucella spp that are frequently associated with horses are $B$. suis and B. abortus (Cvetnic et al, 2005). Humans may become infected when they are exposed to body fluids from a $B$. suis or $B$. abortus infected horse. Most cases of human transmission from horses are in developing countries.

In Egypt, regarding human brucellosis, Hussein et al. (2005) examined 7154 patients at Assiut Fever Hospital examined for Brucella antibodies by slide agglutination test and ELISA-IgM and IgG. They found 
that brucellosis infection was higher in patients from the rural areas $(1.3+/-0.005 \%$ and $1.25+/-0.009 \%$ ) than from urban ones $(1.23+/-0.001 \%$ and $1.12+/-0.01 \%)$ as diagnosed by both agglutination test and ELISA, respectively, and that the prevalence varied significantly between different occupational and age groups. Afifi et al. (2005) showed that the distribution of brucellosis was similar in both rural and urban settings in all parts of Egypt. Fadeel et al. (2006) in the NAMRU-3 examined sera from patients with AFI at 13 fever hospitals across Egypt between 1999 and 2003. They found that the sensitivity and specificity of ELISA for total specific antibodies were $>96 \%$ versus $87 \%$ for TA as compared to the current gold standard method for Brucella microbial culture. Assessment of Brucella antibody classes by ELISA in random subsets of the 5 groups showed significantly high $(\mathrm{p}>0.001)$ levels of anti Brucella IgG (>81\%) and IgM $(>90 \%)$ in groups I and II only. They concluded that ELISA was more suitable for AFI surveillance and clinical settings than blood culture and TA, as being costeffective, easier to use, faster, and the coated plates can be stocked for at least 8 months, providing a potential for field use and automation.

Meky et al. (2007) in Alexandria found that working with animals, breeding goats and eating ice cream bought from street vendors were significantly associated $(\mathrm{P}<$ 0.05 ) with brucellosis by univariate and multivariate analysis. Contact with infected animals and their products was the most important means of transmission. Jennings et al. (2007) in Al Fayoum Governorate conducted population-based surveillance for acute febrile illness (AFI)) among all hospitals and a representative sample of community healthcare providers. AFI patients without obvious etiology were tested for brucellosis by culture and serology. Of 4490 patients 321 (7\%) met brucellosis case definition. The estimated annual incidence per 100000 populations was 64 and 70 in years
2002 and 2003, respectively. The median age of brucellosis patients was 26 years and $70 \%$ were male; $53 \%$ were initially diagnosed as typhoid fever. They added that close contact with animals and consumption of unpasteurized milk products were associated with brucellosis. El Sherbini et al. (2007) in Gharbia Governorate examined 616 inhabitants (aged 3-75 years) and 350 livestock of 97 households in two villages. Positive sera were $0.0 \& 1.7 \%$ in man and $0.0 \& 16 \%$ in livestock, respectively. The calculated sero-prevalence considered the clustering of brucellosis within households was 0.03 for man and 5.2 for livestock. The village variable $(\mathrm{P}=0.07)$ and keeping sheep indoors $(\mathrm{P}=0.01)$ were significant risk factors for human brucellosis, whereas only the village was significant for livestock $(\mathrm{P}<0.001)$. Sheep gave the highest brucellosis positivity among livestock, without detected association between human and livestock brucellosis.

El Kholy et al. (2009) found that PCR positivity increased significantly with the increasing seropositivity titers by using the standard tube agglutination test and reported that $100 \%$ positivity were in the patients with positive blood cultures. They recommended the PCR as a best alternative to brucellosis culture. Mansour et al. (2009) reported the first case of Egyptian Brucella meningitis. Fadeel et al. (2011) in NAMRU3 compared ability of four commer-cially available ELISA kits (Bioquant, IBL, Vircell, and Euroimmun) to diagnose brucellosis in patients from Egypt and the United States. The sensitivities for all kits tested, except Vircell, were greater than $90 \%$ while specificities were variable with the Bioquant assay having a specificity of less than $40 \%$. Detection of $\mathrm{IgG}$ antibody was more sensitive than IgM antibody for diagnosing brucellosis cases but specificity was comparable. Overall, there was good agreement between all of the kits except Bioquant. They concluded that no diagnostic assay was $100 \%$ reliable for brucellosis; serology 
should be considered in tandem with patient history, clinical signs, and other test results. El-Metwally et al. (2011) examined 329 attendances of the out-patients clinics of AlAzhar and Ain Shams Universities Hospitals and Giza Governorate farmers for brucellosis. The patients were 213 (64.75\%) working in dairy farm and/or consumed raw milk, 16 $(14.85 \%)$ used home slaughtering of sheep, and $100(30.4 \%)$ were working in Giza Government Slaughterhouse. Clinically and by ELISA-IgM 259 of 329 were proven brucellosis patients $(77.8 \%)$. Others had schistosomiasis mansoni or toxoplasmosis, or fascioliasis. They reported that signs and symptoms of brucellosis patients were fever (91.5\%), chills (84.1\%), Myalgia (69.5\%), headache $(58.2 \%)$, fatigue $(77.2 \%)$, anorexia $(54.1 \%)$, tachycardia $(38.6 \%)$, hepatoand/or splenomegaly (46.2\%), lymphadenopathy $(19.6 \%)$ lower back abdominal pain $(8.8 \%)$ and/or constitutive symptoms $(13.1 \%)$.

In Egypt, regarding non-human brucellosis, Salem and Mohsen (1997) experimentally considered fish as a susceptible species to brucellosis (B. melitensis biovar) and suggested the possibility of zoonotic transmission. Samaha et al. (2009) compared brucellosis sero-prevalence in cattle with respect to breed, age, and sex, and in humans with history of contact animals. The prevalence in more-than-1-year-old cattle was significantly higher than in less-than-1-year-old cattle. Total sero-prevalence in humans' brucellosis ranged from $5 \%$ to $8 \%$, without seasonal significant differences. Hegazy et al. (2011) used a spatial scanning method to identify areas with significantly higher proportions of seropositive flocks and milk tanks. $12.2 \%$ of sheep and $11.3 \%$ of goats were positive against Brucella spp. and $12.2 \%$ and $12 \%$ of cattle and buffalo milk tanks had antibodies against Brucella spp. They stated that brucellosis was endemic at high levels in all ruminant species in Kafr El Sheikh Governorate. The high intensity of infection transmission among ruminants combined with high livestock and human density and widespread marketing of unpasteurized milk and dairy products may explain why Egypt has one of the highest rates of human brucellosis worldwide.

Coxiella burnetii: C. burnetii, the etiologic agent of Q fever, is a worldwide zoonosis. The most common animal reservoirs are goats, cattle, sheep, cats, and occasionally dogs or horses. Infected mammals shed $C$. burnetii in urine, feces, milk, and birth products. In humans, exposure results from inhalation of contaminated aerosols from parturient fluids of infected mammals, which can be present in the environment, on the coats of newborn animals, or from the placenta. A serosurvey of horses in Uruguay found a positive rate of $5.5 \%$ in 1979 and $21.7 \%$ in 1985 (Marrie, 2003). Q fever (Australian Q fever or Balkan influenza) caused by $\mathrm{C}$. burnetii; is worldwide zoonotic disease in Australia, America, Asia, Africa and parts of Europe (Craig and Edward, 1998). It has been reported in Egypt (Wilson, 1991). C. burnetii is endemic in Mediterranean area and has a wide range of hosts; cattle, sheep, goats, pigs, horses, camels, buffaloes, dogs, cats, pigeons, ducks, geese, fowls and turkeys (Fenga and Pugliese, 2013). Street dogs and cats were considered as sentinel animals for monitoring of $C$. burnetii in surrounding house-hold environment, livestock and stray wildlife (Zborowsky and, Hellmich, 2011).

The clinical presentation of $Q$ fever varies per host species. C. burnetii infection in animals is mainly asymptomatic except for pregnant ruminants in which abortions and stillbirth can occur. In humans, the disease is also mainly asymptomatic, but clinical presentations include acute and chronic Q fever and the post-Q fever fatigue syndrome. Knowledge of the pathogenesis of Q fever in animals and excretion of $C$. burnetii in infected animals is crucial in understanding the transmission routes and risks of human infection: A self-limited flu-like illness Pneumonia Hepatitis. Chronic infection 
most commonly involves the heart as endocarditis (Roest et al, 2013).

In Egypt, Hoogstraal et al. (1967) reported Rickettsia conori, R. prowazeki, and Coxiella burneti infections in rodent hosts and their tick-vector. Mazyad and Hafez (2007) reported antibodies against Coxiella burnetii were estimated among sheep, goats and camels (190), their owners (150 patients with pyrexia of unknown origin) and 30 normal individuals in North Sinai over the 2006 by indirect immounofluorescence assay. Nested polymerase chain reaction was used to detect Com-1 gene (genetic target of C. burnetii) encoding a $27-\mathrm{kDa}$ outer membrane protein in the samples. C. burnetii IFA antibodies (IgM \& IgG) in patients were 8 $(5.3 \%)$ and a healthy control $(3.3 \%)$. The overall was 9 of $180(5.0 \%)$. C. burnetii IgM were detected in $3 / 150(2 \%)$ patients with positive genome, while IgG were detected in 5/150 patients, only the three who had IgM and IgG had positive genome suffered high fever. C. burnetii antibodies were detected in $20(22.5 \%), 12(16.8 \%) \& 4$ $(13.3 \%)$ of sheep, goats, camels, which total 36/190 (18.9\%).

Mosquito-borne disease: Among the mosquito-borne encephalitis viruses, the greatest public health threat in North America are posed by the West Nile, St. Louis encephalitis, and La Crosse encephalitis viruses (show table 1). Venezuelan equine encephalitis virus is of concern in Central and South America, while Japanese encephalitis virus affects persons living or traveling to parts of Asia. Dengue is a rare cause of encephalitis throughout the tropical world (Deresiewicz et al, 1997). Among the tick-borne viruses that cause encepha-litis, tick-borne encephalitis virus has the greatest public health impact worldwide and is of concern to residents of or visitors to northern parts of Eastern Europe and Asia. Powassan virus is a rare, tick-borne cause of encephalitis in the northeastern United States, eastern Canada, and Russia (Erwin et al, 2002). Horses can be infected by Eastern, Western, or Vene- zuelan equine encephalitis virus or West Nile virus (Burgueño et al, 2013). However, although both human and horses may develop encephalitis from each of these agents, infection with Eastern and Western equine encephalitis (EEE and WEE) and West Nile virus results in low or undetectable levels of viremia, thus these hosts do not serve as reservoirs for further spread of the virus. The horse, however, acts as a reservoir of disease for Venezuelan equine encephalitis (VEE) virus (Pisano et al, 2013). WNV, a member of the Japanese encephalitis virus antigenic complex, was first isolated in a blood sample in a patient from the West Nile province of Uganda in 1937. This RNA virus was initially considered of minor public health importance (Gubler, 2007).

In Egypt, Mohammed et al. (1970) examined acute blood samples from 120 children, attending the fever hospital in Alexandria and complaining of fever for the HAI and $\mathrm{CF}$ antibodies against arbovirus antigens; Sindbis, West Nile (WN), Yellow fever, Dengue 1, Sand-fly fever, Quaranfil, Chenuda and Nyamanini. Positive reactions were only detected against Sindbis (4.3\%) and WN (4.3\%) antigens. The convalescent sera obtained from 48 of these children showed a pronounced HAI titer against WN antigen in $14.6 \%$ of them. The same sera showed a lower titer against yellow fever antigen (Asibi strain) which is due to cross-reaction between the two viruses. None of the acute or the convalescent sera showed CF antibodies against Quaranfil, Chenuda or Nyamanini antigens.

Darwish et al. (1987) stated that fever and myalgia are non-specific clinical manifestations of illness which commonly occur in patients with arboviral disease. Such illness is often mis-diagnosed as "influenza". They examined sera samples of 55 patients with fever and myalgia, acute and convalescent in Imbaba Fever Hospital, Giza. Based on viral isolation, and clinically, 4 patients (7\%) had acute arboviral infections. Hemagglutination inhibition and IFA tests showed that one had 
WNV infection, 2 had sand-fly fever virusNaples (SFN), and 1 had sand-fly fever virus-Sicilian (SFS) infection. SFN was isolated from the acute serum sample of 1 of the 2 patients with SFN infection.

Corwin et al. (1992) estimated arboviral, rickettsial, and Hantaan viral antibody in schoolchildren (8- 14 years) from 4 villages in Bilbeis district of the Nile Delta. The antibody prevalence was $9 \%$ for Sicilian sandfly fever, $4 \%$ for RVF, 3\% for WNV and 9\% for Hantaan (HTN) virus. Antibody was found among $22 \%(93 / 418)$ of the same study subjects against Coxiella burnetti, $53 \%$ against Rickettsia typhi, and 37\% against $R$. conorii. Corwin et al. (1993) also examined blood samples from a total 915 persons representing 190 study households. Enzyme immunoassay testing showed that the overall prevalence of IgG antibody was $4 \%$ to sand fly fever Sicilian (SFS), $2 \%$ to sand-fly fever Naples (SFN), 15\% to RVF, $20 \%$ to the WN, and $4 \%$ to Hantaan (HTN) viruses. Antibody was found among $32 \%$ of the same study subjects to C. burnetii, $58 \%$ to $R$. typhi, and $32 \%$ to $R$. conorii. None was in population less than seven years of age and in only $3 \%$ of those $7-12$ years old. But, $26 \%$ of the study population 13-19 years old, who were young children and infants at the time of the outbreak, Geometric mean titers (GMT) ranged from 139 for C. burnetii to 1,305 for RVF, and did not vary significantly by age, except for high titers for RVF in the 20-49-year-old age group.

Abbassy et al. (1993) reported WN virus was detected for three and four days after feeding in $A$. persicus and A. hermanni, respectively, and decreased to undetectable levels in both species. When dose was increased to 10 (6.2), virus was detected until days 6 and 8, respectively. In A. arboreus, virus titers in whole tick homogenates reached a peak of $10(4.0)$ on the $4^{\text {th }}$ day post-feeding and remained constant at 10(3.0) after day 6 throughout the 20 - or 50 day observation periods. No evidence of transstadial transmission from nymph to adult was detected. Larvae from experimentally infected females successfully transmitted virus to clean chicks and virus was recovered from F1 larvae. Virus was present in coxal fluids secreted by infected females after infective meals. They concluded the demonstration of the WN virus infection in experimentally infected $A$. arboreus ticks and documents horizontal and vertical transmission.

Darwish et al. (1996) evaluated three serologic tests for WNV detection. ELISA showed $45 \%$ while HI and IFT indicated 37.6 and $26.4 \%$ positive sera among the tested 178 sera taken from the flooded village, respectively. The positive predictive values for the 3 tests were more than $80 \%$ while the negative predictive ones were different for these tests: $66.7 \%$ for ELISA, $44.1 \%$ and $37 \%$ for HI and IFT, respectively. They concluded that for screening of population in an endemic area, started with ELISA (the more sensitive) followed by HI and/or IFT.

El-Esnawy (2001) examined Egyptian workers at sewage treatment plants (STPs) work and lives in areas, which are highly infested with arthropods. Most of these diseases cause, febrile, influenza like illness, headache, backache, abdominal pain, and fatigue. To determine arboviral etiology in those workers, 264 serum samples were obtained from the workers in four STPs during January and October 1999. ELISA was performed for $\operatorname{IgG} \& \operatorname{IgM}$, to detect the $\mathrm{WN}$, Sindbis (SIN), Rift Valley fever (RVF), Sand-fly Naples (SFN) and Sand-fly Sicilian (SFS) viruses. The results showed that (WN) has highest prevalence $(143 / 264,54.14 \%)$, followed by (SFN) $(58 / 264,21.97 \%)$ then (RVF) $(23 / 264,7.95 \%)$, while, only one recent infection for each of RVF, SFS and SFN $(1 / 264,0.38 \%)$ and 3 persons for SIN viruses. Out of the four STPs Helwan workers' exhibited the highest infection rate for most of the studied arboviruses WN, SFN, SIN and SFS. 
Turell et al. (2002) isolated 33 virus isolates from 36,024 mosquitoes. Viruses were initially identified by indirect fluorescent antibody testing and consisted of 30 flaviviruses (all members of the Japanese encephalitis complex, most probably $\mathrm{WN}$ virus and three alphaviruses (all members of western equine encephalitis complex, most probably Sindbis). The identity of selected viruses was confirmed by reverse transcriptase-PCR and sequencing. Cx. antennatus and $C x$. perexiguus accounted for five $(17 \%)$ and $23(77 \%)$ of the $\mathrm{WN}$ virus isolations, respectively, RVF virus was not isolated from these mosquitoes.. They concluded, that one must remember, that even during a known arbovirus outbreak, other arboviruses might still be circulating and causing disease.

Soliman et al, (2010) found WNV actively circulatied in different areas in Egypt and causing febrile illness in a considerable proportion of individuals in the study sites. Kropman et al. (2012) in the Netherlands reported a 44-year-old female presented with fever and a flaccid paresis of the left leg, following a holiday in Egypt. Prevalence and distribution of huge species mosquitovectors allover Egypt was reported (ElBashier et al, 2006; Mikhail et al, 2009; Shoukry and Morsy, 2011; Morsy, 2012). El-Bahnasawy et al. (2013) gave an overview of the current understanding flaviviruses mainly WNFV. Primary care physician and senior nurse should be able to include the disaster diseases in differential diagnosis of various clinical conditions, and should take a thorough history to request specific dependable laboratory test(s) as soon as possible, and positive patient should be transferred to the fever hospital.

Equine encephalitis: Large outbreaks of Western equine encephalitis in humans and horses occurred in the western United States in the 1950s and 1960s. However, a declining horse population, equine vaccination, and improved vector control have reduced the incidence of the disease. Infection of avian species results in a viremia of sufficient magnitude and frequency to maintain a reservoir of infected mosquitoes. Infection of horses causes low level viremia and thus the horse is not a reservoir of WEE or EEE virus (Gibbs, 2005).

In contrast, horses serve as the primary amplification hosts for Venezuelan equine encephalitis (VEE) virus without which there would be little human disease (Perri et al, 2003). Effective prevention of both human and equine disease can be accomplished by immunizing equines. Mosquitoes are required as a vector for human transmission. VEE has a widespread geographic distribution from Florida to South America (Carrara et al, 2007).

The mosquito or tick becomes infected when feeding on the blood of the viremic animal. The virus then replicates in the mosquito or tick tissues, ultimately infecting the salivary glands. The mosquito or tick transmits the virus to a new host when it injects infective salivary fluid while taking a blood meal (Erwin et al, 2002). Human disease occurs after an incubation period of one to six days, and is heralded by a brief febrile illness of sudden onset, accompanied by malaise, nausea or vomiting, headache, and myalgia. Less than $0.5 \%$ of adults and less than 4 percent of children develop encephalitis, characterized by nuchal rigidity, seizures, coma, and paralysis. Long-term sequelae and fatalities are uncommon. In Egypt Badiali et al. (1966) gave a preliminary report on rabies in suspected equine encephalomyelitis cases. Abdel-Gawad et al. (2014) reported equine herpesvirus type 1 (EHV-1) was detected in an Indian rhinoceros (Rhinoceros unicornis), which was euthanized because of severe neurological disease.

Saliva transmission: Saliva can transmit and contaminate bite wounds, skin abrasions, or mucous membranes.

Rabies: Rabies is a preventable zoonotic disease. The etiologic agents are neurotropic RNA viruses belonging to the Family Rhabdoviridae, Genus Lyssavirus. In addi- 
tion to the type species, rabies virus, at least 10 other rabies-related viruses can cause fatal encephalitis that is clinically indistinguishable from classical rabies, and formal inclusion of additional lyssavirus members is anticipated (WHO, 2005). Almost all cases of rabies are transmitted from rabid animals through a bite. In rare cases, rabies results from a non-bite exposure (e.g., aerosolized virus) or transplantation of tissue from a donor with unrecognized rabies (Davis et al, 2007). The clinical diagnosis of rabies is straightforward in developing countries when a nonimmunized patient presents after a bite by a known rabid animal. In developed countries, some patients may have an unrecognized exposure (e.g., to a bat) or are unaware of the risks of exposure and did not receive postexposure prophylaxis (Jackson, 2005). Laboratory diagnosis of rabies requires several specimens (e.g., saliva, skin, serum, CSF) and multiple testing modalities, since the sensitivity of any single test is limited. Serum antibody titers, for example, may not test positive until rather late in the course of illness, if at all. However, the sensitivity of the combination of tests approaches $100 \%$, depending upon specimen quality, timing of collection, and diagnostic expertise. Virus shedding can be intermittent; as a result, serial samples should be obtained (Dacheux et al, 2008). Although rare, horses can become infected and die with rabies (Feder et al, 1988). Human rabies is rare in the United States, with only 47 cases reported between 1990 and 2005 (Potter et $a l, 2007)$. However, rabies should be considered in the differential diagnosis of patients presenting with acute progressive encephalitis regardless of a history of an animal bite. Because of the nonspecific early symptoms, other more common infectious and noninfectious disorders (e.g., encephalitis caused by arboviruses or enterovirus and Guillain-Barré syndrome or vasculitis) should be ruled out (Rupprecht et al, 2002).

Aylan et al. (2011) stated that rabies is a threat in all parts of the world where animal reservoirs persists, including Eastern Europe and the Middle East. Rabies experts from seven Middle East and Eastern European countries (Croatia, Egypt, Georgia, Iran, Serbia, Turkey, and Ukraine) met for two days in Istanbul, Turkey (June 8-9, 2010), to exchange information on the epidemiological situation concerning human and animal rabies in their respective countries and to discuss strategies for rabies elimination and control. They added that in Egypt, animal rabies is present both in urban areas and rural settlements. Stray dogs are the main transmitters to other animals and humans. The situation has been stable for the last 10 years with an annual number of 80 human rabies cases.

On the other hand, equines act as animal hosts for many diseases endemic in Egypt.

Fascioliasis $F$. gigantica and $F$. hepatica tops all the zoonotic helminthes worldwide.

Haridy et al. (2002) carried out a preliminary coprologic examination of donkeys and horses in eight centers of Gharbia governorate. The overall rate in donkeys was $3.03 \%$, in horses was $1.5 \%$, and in mules $0.0 \%$. Horses $2 / 74 \quad(2.70 \%)$ and $1 / 26$ (3.86\%) were infected in Zefta and El Mahala El Kobra centers respectively. None of the horses was infected in other six centers. On the other hand, donkeys showed infection rates of $4.6 \%, 7.6 \%$ and $9.09 \%$ in the centers of Santa, Zefta and El Mahala El Kobra respectively. They concluded that according to population density of donkeys and horses in Gharbia governorate, donkeys represent the $4^{\text {th }}$ rank in number. So, donkeys and to a very less extend, horses should be considered within the preventive and control measures of zoonotic fascioliasis. Morsy et al. (2005) in Tamyia Center, Al-Fayoum Governorate, examined some farm animals for natural infection with Fasciola species. The results showed $40 \%$ infection in sheep, $20 \%$ in buffalos, $6.7 \%$ in donkeys and zero\% in horses. Haridy et al. (2007) postmortum examination of 88 donkeys used as gargantuan meal in the Zoo at Giza revealed 
hepatic fascioliasis in 15 (17.05\%). AntiFasciola antibodies by ELISA showed positivity in 12/15 with crude worm antigen, and positivity in $14 / 15$ with locally prepared Fasciola excretory-secretory (Fges) antigen.

Toxoplasmosis: $T$. gondii is one of the important zoonotic parasites of worldwide. ElGhaysh (1998) Menoufia Province reported ELISA $T$. gondii antibodies in 121 adult donkeys. Shaapan and Ghazy (2007) inoculated Portions of heart, liver, skeletal and diaphragmatic muscles obtained from 150 slaughtered horses at Giza-Zoo abattoir to mice and cats. T. gondii tachyzoites were isolated successfully from the peritoneal exudates of mice 6-8 days post inoculation with pooled horse tissues. T. gondii tissue cysts containing bradyzoites were detected in the impression smears of mice brain about 45th days post infection. The oocysts were detected in feces of cats 3-6 days post feeding on horse tissues containing tissue cysts, which were sporulated within 3-5 days in $2.5 \%$ Potassium dichromate. A total of $79 / 150$ horse meat samples were infected with an incidence rate of $52.6 \%$. Ghazy et al. (2007) used crude antigen of Toxoplasma gondii tachyzoites from horse tissues (LA) to detect antibodies in horses, which showed good diagnostic efficiency (38.1\%) by ELISA. To increase this efficiency, two fractions were obtained from LA by $\mathrm{CNBr}-$ Sepharose 4B affinity column chromatography named; unbound (LAunb) and bound (LAb). LAb showed the highest diagnostic potency $(51.7 \%)$, while LAunb showed the lowest one $(31.7 \%)$ using ELISA. The electrophoretic profile of LA (12 bands), LAb (6 bands) and LAunb (6 bands) showed molecular weights from 25.1 to $184.3 \mathrm{kDa}$. The immunoreactive bands of each of the three antigen were identified with infected horse sera by immunoblot assay. Four immunogenic bands of 155.8, 115.1, 83.2 and $66.2 \mathrm{kDa}$ were identified in LAb and probably were responsible for the highest diagnostic potency. Examination of horse sera by IFAT at a dilution of 1: 64 and Modified
Agglutination Test (MAT) at a dilution of 1: 25 revealed that $170(40.5 \%)$ and 202 (48.1\%) had antibodies against $T$. gondii, respectively. Haridy et al. (2009) examined draught horses (3-15 years) including 90 males and 10 females in the first half of the year $2009 T$. gondii. The overall ELISAantibodies were $25 \%$ in Greater Cairo, $50 \%$ (females) and $22.2 \%$ (males). Haridy et al. (2010) in greater Cairo examined 75 females \& 25 males aged between 3-10 years working donkeys, ELISA antibodies of $T$. gondii found $45 / 100(45 \%)$, also milk obtained from 7/15 (46.3\%). females were positive.

Echinoccocus granulosus causes hydatid cysts in man and animals. Haridy et al. (2008) macroscopically and microscopically reported hepatic hydatidosis in 17 out of 160 slaughtered donkeys. Aboelhadid et al. (2013) on post-mortem inspection at the zoo of Beni-Suef examined 145 donkeys for hydatid cysts. Ten had hydatid cysts; mainly in their livers. Molecular identification they were Echinococcus equinus (G4 genotype). An alignment of ND1 and CO1 partial nucleotide sequences with G4 partial nucleotide sequences revealed replacement of $G$ at position 105 with $\mathrm{A}$ and replacement of $\mathrm{A}$ at position 276 with $G$ respectively. It can be concluded that the donkeys involved in this study were harboring E. equinus.

Other reported cases: Morsy et al. (2001) in Aswan District reported Tabanus taeniola and Haematopota minuscula were trapped on camels and equines at daytime during summer of 2000, they added that many species of Tabanus and few species of Haematopota were reported before in Egypt. Of zoonotic interest was the detection of $T$. $e v$ ansi in a worker caring for camels as indicated by $T$. evansi ELISA-antibodies and the presence of $T$. evansi in stained blood smears, the human case was successfully treated as indicated clinically, parasitologically and serologically (Haridy et al, 2011). Abo-Shehada et al. (1999) in Jordan reported that $T$. evansi-infected camels and horses showed all the clinical signs known for Sur- 
ra and that all infected camels stared at the sun. Berlin et al. (2010) reported an outbreak of trypanosomoasis caused by $T$. $e v-$ ansi involving horses, camels and donkeys occurred in a farm in Israel. Most of the camels on the farm $(8 / 10 ; 80 \%)$ were diagnosed with $T$. evansi infection whereas infection was less prevalent in the horses $(3 / 7$; $43 \%)$ and donkeys $(6 / 13 ; 46 \%)$. Recurrence of infection was documented in one camel 4 months post treatment. Berlin et al. (2012) reported that seroprevalence of $T$. evansi in the Arava and Dead Sea region was 6.5\% $(9 / 139)$ in the first sampling compared with $4.1 \%(5 / 122)$ in the second, whereas the prevalence of RDB-positivity was $18.7 \%$ (26/139) in the first sampling and only $0.8 \%$ $(1 / 122)$ in the second. All horses were asymptomatic except for one horse from the Arava and Dead Sea region that demonstrated clinical signs of surra combined with positive serology and RDB. They concluded that surra should be considered an important differential diagnosis in horses and other domestic animals in Israel with chronic weight loss, edema or neurological signs.

Farah et al. (2003) used twenty-three blood samples; five from five naturally infected horses with Babesia equi, and eighteen from asymptomatic horses with equine babesiasis from different localities in Egypt. All samples were subjected to microscopic examination, IFA and PCR. The carrier animals were microscopically detected in 7 out of 18 samples $(38.8 \%)$ and in 9 of 18 by using IFA (50\%), whereas PCR revealed that 14 samples were positive (78\%). Two synthetic oligonucleotide primers, based on the B. equi merozoite antigen gene (EMA-1) were used. A 819 bps DNA fragment is specifically amplified from the gene encoding EMA-1 of B. equi.

Marzok and Desouky (2008) in seven donkeys reported a unilateral eye showing motile white worms in the aqueous humor, which were surgically removed from the eye anterior chamber of the in five of them.
Morsy (2008) by ultrastructure illustration reported some pathological pictures of Gastrodicus aegyptiacus in Egyptian horses

El-Seify et al. (2010) in postmortem examination of 54 adult donkeys slaughtered for the carnivore animals in Kafr El-Sheikh Zoological Garden, reported Dictyocaulus arnfieldi in their lungs.

\section{Conclusion}

Human communities often are an inadvertent source of food, water, and other resources to native species of animals and birds. Many people worldwide particularly in the developing countries utterly dependent on horses, donkeys and mules, there is nothing more important than caring for these group of animals that allow human welfare to work, families to carry on their life

Undoubtedly, the interrelationships among people in gregarious species can have profound effects on the animals' behavior, physiology, health and role as reservoir of zoonotic diseases. Captive housing should address the social needs of such species because failure to do so can result in the development and expression of abnormal behavior. Extensive work concerning the zoonosis from birds and animals other than dogs, cats and equines is in ongoing and will be published in due time elsewhere.

There are no general rules applicable to all social species, however. Determining the social conditions needed for members of any animal species requires an ethological approach that evaluates the sensory, cognitive, and ecological characteristics of animal and considers those characteristics in the design of captive housing, research and control. One must remember what God Said "And (He made) horses and mules and asses that you might ride upon them and as an ornament; and He creates what you do not know (Hallowing Quran 16:8)"

Additionally, all over the world people of humane societies should consider well treating of domestic animals through following 
them up and treating infected ones with any sort of parasites or different pathogenic diseases. Protect your life by protecting domestic animal life.

\section{References}

Abbassy, MM, Osman, M, Marzouk, AS, 1993: West Nile virus (Flaviviridae: Flavivirus) in experimentally infected Argas ticks (Acari: Argasidae). Am. J. Trop. Med. Hyg. 48, 5:726-37.

Abdel-Gawad, A, Azab, W, Damiani, AM, Baumgartner, K, Will, H, et al, 2014: Zebraborne equine herpesvirus type 1 (EHV-1) infection in non-African captive mammals. Vet. Microbiol. 169, 1/2:102-6

Abdou, AG, Harba, NM, Afifi, AF, Elnaidany, NF, 2013: Assessment of Cryptosporidium parvum infection in immunocompetent and immunocompromised mice and its role in triggering intestinal dysplasia. Int. J. Infect. Dis. 17, 8:e593-600.

Aboelhadid, SM, El-Dakhly, KM, Yanai, T, Fukushi, H, Hassanin, KM, 2013: Molecular characterization of Echinococcus granulosus in Egyptian donkeys. Vet. Parasitol. 193, 1/3:292-6

Abo-Shehada, MN, Anshassi, H, Mustafa, G, Amr, Z, 1999: Prevalence of Surra in camels and horses in Jordan. Prev. Vet. Med. 38, 4:28993.

Abou Holw, SA, Anwar, MM, Heshmat M G, Enany AY, Rashad MM, 2012: Effect of concommitant Helicobacter pylori infect- ion in patients with Giardia lamblia in Egy-pt. J. Egypt. Soc. Parasitol. 39, 2:439-46.

Afifi, S, Earhart, K, Azab, M.A, et al, 2005: Hospital-based surveillance for acute febrile illness in Egypt: A focus on community-acquired bloodstream infections. Am. J. Trop. Med. Hyg. 73, 2:392-9.

Ahmed, AM, Shimamoto, T, 2014: Isolation and molecular characterization of Salmonella enterica, Escherichia coli O157:H7 and Shigella spp. from meat and dairy products in Egypt. Int. J. Food Microbiol. 168/ 169:57-62

Aho, R, 1983: Saprophytic fungi isolated from the hair of domestic and laboratory animals with suspected dermatophytosis. Mycopathologia 83:65-72.

Al-Eissa, YA, Al-Mofada, SM, 1992: Congenital brucellosis. Pediatr. Infect. Dis. J. 11:667.
Aylan, O, El-Sayed, AF, Farahtaj, F, Janani, AR, Lugach, O, et al, 2011: Report of the first meeting of the middle East and eastern europe rabies expert bureau, istanbul, Turkey (june 8-9, 2010). Adv. Prev. Med. 2011;2011:812515.

Badawy, AA, Gneidy, MR, Ghoniemy, A E, 2012: Acute diarrhea among military rec-ruits. J. Egypt. Soc. Parasitol. 42, 2: 309-20.

Badiali, L, Ferris, DH, 1966: A prelimin- ary report on rabies in suspected equine encephalomyelitis cases in the United Arab Republic. Bull WHO 34, 5: 797-8.

Berlin, D, Nasereddin, A, Azmi, K, Ereqat, S, Abdeen, Z, et al, 2010: Longitudinal study of an outbreak of Trypanosoma evansi infection in equids and dromedary camels in Israel. Vet. Parasitol. 174, 3/4:317-22.

Berlin, D, Nasereddin, A, Azmi, K, Ereqat, S, Abdeen, Z, et al, 2012: Prevalence of Trypanosoma evansi in horses in Israel evaluated by serology and reverse dot blot. Res. Vet. Sci. 93, 3:1225-30.

Bildik, HN, Takeı, S, Yurdakök, M, Kara, A, 2013: Neonatal sepsis due to Rhodococcus equi in two preterm infants. Turk. J. Pediatr. 55, 2:229-31.

Brzank, M, Wollenhaupt, J, 2013: Infectioninduced reactive arthritis: etiopathogenesis, clinical spectrum, therapy. Z. Rheumatol. 72, 10:977-85.

Burgueño, A, Spinsanti, L, Díaz, LA, Rivarola, ME, Arbiza, J, et al, 2013: Seroprevalence of St. Louis encephalitis virus and West Nile virus (flavivirus, flaviviridae) in horses, uruguay

Cacciò, S, Pozio, E, 2001: Molecular identification of food-borne and water-borne protozoa. Southeast Asian J. Trop. Med. Pub. Hlth. 32, 2:S156-8.

Carrara, AS, Coffey, LL, Aguilar, PV, Moncayo, AC, Da Rosa, AP, et al, 2007: Venezuelan equine encephalitis virus infection of cotton rats. Emerg. Infect. Dis.13, 8:1158-65.

CDC, 2007: Bio-safety in Microbiological and Biomedical Laboratories, $5^{\text {th }}$ edition. Washington, DC: US Department of Health and Human Services, CDC, NIH: at www. cdc.gov/od/ ohs/biosfty/bmbl5/bmbl5toc.htm

CDC, 2007: Guidelines for Environmental Infection Control in Health-Care Facilities 
(http://www.cdc.gov/ncidod/dhqp/id_Cdiff_excerpts.html).

Corwin, A, Habib, M, Olson, J, Scott, D, Ksiazek, T, 1992: Prevalence of arboviral, rickettsial, and Hantaan-like viral antibody among schoolchildren in the Nile river delta of Egypt. Trans. R. Soc. Trop. Med. Hyg. 86, 6:677-9.

Corwin, A, Habib, M, Watts, D, Darwish, M, Olson, J, et al, 1993: Community-based prevalence profile of arboviral, rickettsial, and Hantaan-like viral antibody in the Nile River Delta of Egypt. Am. J. Trop. Med. Hyg. 48, 6:776-83.

Craig, EG, Edward, BB, 1998: Rocky Mountain Spot-ted Fever, Q fever and Typhus. In: Craig, E.G. Infectious Diseases of the Dog and Cat. W.B. Saunders, Philadelphia.

Cvetnic, Z, Spicic, S, Curic, S, et al, 2005: Isolation of Brucella suis biovar 3 from horses in Croatia. Vet. Rec. 156:584-94.

Dacheux, L, Reynes, JM, Buchy, P, et al, 2008: A reliable diagnosis of human rabies based on analysis of skin biopsy specimens. Clin. Infect. Dis. 47:1410-18.

Darwish, M, el-Khashaab, TH, Mos- tafa, A, Hamid, TA, Shope, R, 1996: A compa- rative study of serological techniques for detection of West Nile virus antibodies. J. Egypt. Pub. Hlth. Assoc. 71, 3/4:201-11.

Darwish, MA, Feinsod, FM, Scott, RM, Ksiazek, TG, Botros, BA, 1987: Arboviral causes of non-specific fever and myalgia in a fever hospital patient population in Cairo, Egypt. Trans. Roy. Soc. Trop. Med. Hyg. 81, 6:1001-3.

Davis, AD, Rudd, RJ, Bowen, RA, 2007: Effects of aerosolized rabies virus exposure on bats and mice. J. Infect. Dis. 195:1144-50.

Delaloye, J, Merlani, G, Petignat, C, Wen-ger, A, Zaman, K, et al, 2004: Nosocomial nontyphoidal salmonellosis after antineoplastic chemotherapy: reactivation of asym-ptomatic colonization? Eur. J. Clin. Microbiol. Infect. Dis. 23, 10:751-8.

Deresiewicz, RL, Thaler, SJ, Hsu, L, Zamani, AA, 1997: Clinical and neuroradiographic manifestations of eastern equine encephalitis. N. Engl. J. Med. 336:1867.

Dizdar, V, Spiller, R, Singh, G, Hanevik, K, Gilja, OH et al, 2010: Relative impor- tance of abnormalities of CCK and 5-HT (serotonin) in Giardia-induced post-infec-tious irritable bowel syndrome and functional dyspepsia. Aliment. Pharmacol. Ther. 31, 8:883-91.

Dubberke, ER, Reske, KA, Olsen, MA, et al, 2008: Short- and long-term attributable costs of Clostridium difficile-associated disease in nonsurgical inpatients. Clin. Infect. Dis. 46:497.

El Kholy, AA, Gomaa, HE, El Anany, M G, Abd-El Rasheed, E, 2009: Diagnosis of human brucellosis in Egypt by polymerase chain reaction. East. Mediterr. Hlth. J. 15, 5: 1068-74.

El Sherbini, A, Kabbash, I, Schelling, E, El Shennawy, S, Shalapy, N, et al, 2007: Seroprevalence and local variation of human and livestock brucellosis in two villages in Gharbia Governorate, Egypt. Trans. R. Soc. Trop. Med. Hyg. 101, 9:923-8.

El-Bahnasawy, MM, Khater, MKM, Mor-sy, TA, 2013: The mosquito borne West Nile Virus infection: Is it threating to Egypt or a neglected endemic disease? J. Egypt. Soc. Parasitol. 43, 1:87-102

El-Bashier, ZM, Hassan, MI, Mangoud, A M, Morsy, TA, Mohammad, KA, 2006: A preliminary pilot survey (Culexpipiens), Sharkia G., Egypt. J. Egypt. Soc. Parasitol. 36, 1:81-92.

El-Esnawy, NA, 2001: Infection by certain arboviruses among workers potentially at risk of infection. J. Egypt. Pub. Hlth. Assoc. 76, 3/4:169-82.

EI-Ghaysh A, 1998: Seroprevalence of Toxoplasma gondii in Egyptian donkeys using ELISA. Vet. Parasitol. 80, 1:71-3.

El-Metwally, MT, Elwan, MA, El-Bahnasawy, MM, Khalil, HHM, Sabah, AAA, Morsy, ATA, 2011: Zoonotic brucellosis: An underestimated or misdiagnosed disease in Egypt. J. Egypt. Soc. Parasitol. 41, 1:35-46

El-Mohammady, H, Mansour, A, Shahe- en, HI, Henien, NH, Motawea, MS, et al, 2012: Increase in the detection rate of viral and parasitic enteric pathogens among Egy-ptian children with acute diarrhea. J. Infect. Dev. Ctries. 6, 11:774-81.

El-Seify, MA, Harfoush, MA, El-Shaha-wy, IS, 2010: Biological aspects on Dictyocaulus arnfieldi. J. Egypt. Soc. Parasitol. 40, 2:395-400

El-Shamy, M, Ahmed, AI, 2008: The effects of maternal brucellosis on pregnancy outcome. J. Infect. Dev. Ctries. 2, 3:230-4.

Erwin, PC, Jones, TF, Gerhardt, RR, et al, 2002: La Crosse encephalitis in eastern Tennes- 
see: clinical, environmental, and entomological characteristics from a blinded cohort study. Am. J. Epidemiol.155:1060-9.

Farah, AW, Hegazy, NA, Romany, MM, Soliman, YA, Daoud, AM, 2003: Molecular detection of Babesia equi in infected and carrier horses by polymerase chain reaction. Egypt. J. Immunol. 10, 2:73-9.

Feder, HM, Nelson, RS, Cartter, ML, Sadre, I, 1988: Rabies prophylaxis following the feeding of a rabid pony. Clin. Pediatr. (Phila) 37:477-82.

Fenga, C, Pugliese, M, 2013: Endemic zoonosis in Mediterranean area. G. Ital. Med. Lav. Ergon. 35, 4:347-9

Ghazy, AA, Shaapan, RM, Abdel-Rah-man, EH, 2007: Comparative serological diagnosis of toxoplasmosis in horses using locally isolated Toxoplasma gondii. Vet. Parasitol. 145, 1/2:31-6 Gibbs, EP, 2005: Equine viral encephalitis. Equine Vet J 1976; 8:66. Krebs, JW. J. Am. Vet. Med. Assoc. 227:1912-20.

Giguère, S, Cohen, ND, Chaffin, MK, Slo-vis, NM, Hondalus, MK, et al, 2011: Diagnosis, treatment, control, and prevention of infections caused by Rhodococcus equi in foals. J. Vet. Int. Med. 25, 6:1209-20.

Gubler, DJ, 2007: The continuing spread of West Nile virus in the western hemisphere. Clin. Infect. Dis. 45:1039-44.

Haridy, FM, Morsy, TA, Gawish, NI, Antonios, TN, Abdel Gawad, AG, 2002: The potential reservoir role of donkeys and horses in zoonotic fascioliasis in Gharbia Governorate, Egypt. J. Egypt. Soc. Parasitol. 32, 2: 561-70.

Haridy, FM, Abdel Gawad, AG, Ibrahim, BB, Hassan, AA, El-Sherbi, GT, et al, 2008: Zoonotic hydatidosis in donkeys: post mortum examination in the Zoo, Giza, Egy-pt. J. Egypt. Soc. Parasitol. 38, 1:305-12.

Haridy, FM, Morsy, GH, Abdou, NE, Mo rsy, TA, 2007: Zoonotic fascioliasis in donkeys: ELISA (Fges) and postmortum examination in the Zoo, Giza, Egypt. J. Egypt. Soc. Parasitol. 37, 3:1101-10.

Haridy, FM, Shoukry, NM, Hassan, AA, Morsy, TA, 2009: ELISA-seroprevalence of Toxoplasma gondii in draught horses in Greater Cairo, Egypt. J. Egypt. Soc. Parasitol. 39, 3:8216.
Haridy, FM, Saleh, NM, Khalil, HH, Mo-rsy, TA, 2010: Anti-Toxoplasma gondii antibodies in working donkeys and donkey's milk in greater Cairo, Egypt. J. Egypt. Soc. Parasitol. 40, 2:45964.

Haridy, FM, El-Metwally, MT, Khalil, H HM, Morsy, TA, 2011: Trypanosoma evan- si in dromedary camel: With a case report of zoonosis in Greater Cairo, Egypt. J. Egypt. Soc. Parasitol. 41, 1:65-76

Hegazy, YM, Moawad, A, Osman, S, Rid-ler, A, Guitian, J, 2011: Ruminant brucellosis in the Kafr El Sheikh Governorate of the Nile Delta, Egypt: prevalence of a neglected zoonosis. PLoS Negl. Trop. Dis. 5, 1:e944.

Hoogstraal, H, Kaiser, MN, Ormsbee, R A, Osborn, DJ, Hemly, I, et al, 1967: Hyalomma (Hyalommina) rhipicephaloides Neumann (Ixodoidea: Ixodidae): its identity, hosts, and ecology, and Rickettsia conori, R. prowazeki, and Coxiella burneti infections in rodent hosts in Egypt. J. Med. Entomol. 4, 4:391-400.

Hussein, AA, Sayed, AS, EI Feki, MA, 2005: Seroepidemiological study on human brucellosis in Assiut Governorate. Egypt. J. Immunol. 12, $1: 49-56$.

Ibrahim, AMA, 2014: Prevention and control of Clostridium difficile in hospitals. J. Egypt. Soc. Parasitol. In Press.

Jackson, AC, 2005: Recovery from rabies. N. Engl. J. Med.; 352:2549-54.

Jennings, GJ, Hajjeh, RA, Girgis, FY, Fadeel, MA, Maksoud, MA, 2007: Brucellosis as a cause of acute febrile illness in Egypt. Trans. Roy. Soc. Trop. Med. Hyg. 101, 7:707-13.

Juckett, G, 1997: Pets and Parasites. Am. Fam. Physician. 56, 7:1763-8.

Kotloff, KL, Wasserman, SS, Losonsky, GA, et al, 2001: Safety and immunogenicity of increasing doses of a Clostridium difficile toxoid vaccine administered to healthy adults. Infect. Immun. 69:988-94.

Madewell, BR, Tang, YJ, Jang, S, et al, 1995: Apparent outbreaks of Clostridium difficileassociated diarrhea in horses in a veterinary medical teaching hospital. J. Vet. Diagn. Invest. 7:343-52.

Mahmoud, MS, Salem, AA, Rifaat, MM, 2004: Human giardiasis as an etiology of skin allergy: the role of adhesion molecules and interleukin-6. J. Egypt. Soc. Parasitol. 34, 3:723-37. 
Mansour, AM, Nakhla, II, Sultan, YA, Frenck, RWJr, 2009: Brucella meningitis: First re-ported case in Egypt. East. Mediterr. Hlth. J. 15, 4:1040-4.

Marrie, TJ, 2003: Coxiella burnetii pneumonia. Eur. Respir. J. 21:713-20.

Marzok, MA, Desouky, AR, 2008: Ocular infection of donkeys (Equus asinus) with Setaria equina. Trop. Anim. Hlth. Prod. 41, 6:859-63.

Mazyad, SAM, Hafez, AO, 2007: Q fever (Coxlella burnetii) among man and farm animals in North Sinai, Egypt. J. Egypt. Soc. Parasitol. 37, 1:135-42

McDonald, LC, 2005: Clostridium difficile: Responding to a new threat from an old enemy. Infect. Control Hosp. Epidemiol. 26: 672-80.

McKenzie, DM, Diffay, BC, 2000: Diarrhoea associated with cryptosporidial oocyst shedding in a quarter-horse stallion. Aust. Vet. J. 78:2732.

Meky, FA, Hassan, EA, Abd-El-Hafez, A M, Aboul Fetouhl, AM, El-Ghazali, SM, 2007: Epidemiology and risk factors of brucellosis in Alexandria governorate. East. Mediterr. Hlth. J. 13, 3:677-85.

Mikhail, MW, Al-Bursheed, KhM, AbdElHalim, AS, Morsy, TA, 2009: Studies on mosquito borne diseases in Egypt and Qatar. J. Egypt. Soc. Parasitol. 39, 3:745-56.

Mohamed, AM, Abou El-Ella, GA, Nasr, EA, 2009: Phenotypic and molecular typing of tuberculous and non-tuberculous Mycobacterium species from slaughtered pigs in Egypt. J. Vet. Diagn. Invest. 21, 1:48-52.

Mohammed, YS, Gresiková, M, Adamyo- vá, K, Ragib, AH, el-Dawala, K, 1970: Studies on arboviruses in Egypt. II. Contribution of arboviruses to the aetiology of undiagnosed fever among children. J. Hyg. (Lond). 68, 3:491-5.

Morsy, GH, 2008: Ultrastructure and some pathological pictures of Gastrodicus aegyptiacus (Cobbold, 1876) in Egyptian horses. J. Egypt. Soc. Parasitol. 38, 3:957-64.

Morsy, TA, 2012: Insect bites and what is eating you? J. Egypt .Soc. Parasitol. 42, 2: 291-308.

Morsy, TA, Habib, KS, 2001: Two species of tabanids (order: Diptera) in Aswan District, Egypt. J. Egypt. Soc. Parasitol. 31, 2: 429-32

Morsy, TA, Salem, HS, Haridy, FM, Ri-faat, MM, Abo-Zenadah, NY, et al, 2005: Farm animals' fascioliasis in Ezbet El-Bakly (Tamyia
Center) Al-Fayoum Governorate. J. Egypt. Soc. Parasitol. 35, 3:825-32.

Mousa, KM, Abdel-Tawab, AH, Khalil, H H, El-Hussieny, NA, 2010: Diarrhea due to parasites particularly Cryptosporidium parvum in great Cairo, Egypt. J. Egypt. Soc. Parasitol. 40, 2:439-50.

Mulè, A, Petrone, G, Santoro, A, Sanguinetti, M, Meacci, E, et al, 2012: Pulmonary malacoplakia at early stage: use of polymerase chain reaction for detection of Rhodococcus equi. Int. J. Immunopathol. Pharmacol. 25, 3:703-12.

Musher, DM, Musher, BL, 2004: Contagious acute gastrointestinal infections. N. Engl. J. Med. 351:2417-24.

Muto, CA, Blank, MK, Marsh, JW, et al, 2007: Control of an outbreak of infection with the hyper-virulent Clostridium difficile BI strain in a university hospital using a comprehensive "bundle" approach. Clin. Infect. Dis. 45:1266-9.

Myers, EM, Ward, SL, Myers, JP, 2012: Lifethreatening respiratory pasteurellosis associated with palliative pet care. Clin. Infect. Dis. 54, 6:e55-7.

Nath, SR, Mathew, AP, Mohan, A, Anila, KR, 2013: Rhodococcus equi granulomatous mastitis in an immunocompetent patient. J. Med. Microbiol. 62, 8:1253-5.

Nyberg, KA, Vinnerås, B, Lewerin, SS, Kjellberg, E, Albihn, A, 2011: Treatment with $\mathrm{Ca}$ $(\mathrm{OH}) 2$ for inactivation of Salmonella typhimurium and Enterococcus faecalis in soil contaminated with infected horse manure. J. Appl. Microbiol. 110, 6:1515-23.

Olson, ME, Thorlakson, CL, Deselliers, L, et al, 1997: Giardia and Cryptosporidium in Canadian farm animals. Vet. Parasitol. 68: 375-82.

Parslow, RA, Jorm, AF, 2003: Pet ownership and risk factors for cardiovascular disease: another look. Med. J. Aust. 179:466-74.

Perri, S, Greer, CE, Thudium, K, Doe, B, Legg, H, et al, 2003: An alphavirus replicon particle chimera derived from Venezuelan equine encephalitis and Sindbis viruses is a potent gene-based vaccine delivery vector. J. Virol. 77, 19:10394-403.

Pickering, LK, Marano, N, Bocchini, JA, Angulo, FJ, 2008: Exposure to nontraditional pets at home and to animals in public settings: Risks to children. Pediatrics 122: 876 . 
Pisano, MB, Oria, G, Beskow, G, Aguilar, J, Konigheim, B, et al, 2013: Venezuelan equine encephalitis viruses (VEEV) in Argentina: serological evidence of human infection. PLoS Negl. Trop. Dis. 7, 12:e2551

Potter, TM, Hanna, JA, Freer, L, 2007: Human North American river otter (Lontra canadensis) attack. Wilderness Environ. Med. 18, $1: 41-4$.

Risk, H, El Shazly, AM, Soliman, M, Mohammad, AA, El Sharkawy, EMA, Mor-sy, AT A, 2004: Genotyping of human giardiasis in relation to anti-Giardia secretory IgA and mucosal histo-pathology. J. Egypt. Soc. Parasitol. 34, 2:471-81.

Roest, HI, Bossers, A, van Zijderveld, FG, Rebel, JM, 2013: Clinical microbiology of Coxiella burnetii and relevant aspects for the diagnosis and control of the zoonotic disease Q fever. Vet. Q. 33, 3:148-60.

Rosen, T, Jablon, J, 2003: Infectious thre-ats from exotic pets: dermatological implications. Dermatol. Clin. 21:229-34.

Roug, A, Byrne, BA, Conrad, PA, Miller, WA, 2013: Zoonotic fecal pathogens and antimicrobial resistance in county fair animals. Comp. Immunol. Microbiol. Infect. Dis. 36, 3: 303-8.

Rupprecht, CE, Hanlon, CA, Hemachudha, T, 2002: Rabies re-examined. Lancet Infect. Dis. 2:327.

Sabah, AA, Aly, AM, Abdel Tawab, AH, Arafa, WA, 2008: Brucellosis in Egyptian female patients. J. Egypt. Soc. Parasitol. 38, 2:671-8.

Sabry, AA, Morsy, ATA, Morsy, TA, 2012: Zoonoses from dogs with special reference to Egypt. J. Egypt. Soc. Parasitol. 42, 3:583-604.

Sabry, AA, Fouad, MAH, Morsy, ATA, 2013: Zoonoses from cats: with special reference to Egypt. J. Egypt. Soc. Parasitol. 43, 1:429-46

Said, MM, El-Mohamady, H, El-Beih, F M, Rockabrand, DM, Ismail, TF, et al, 2010: Detection of gyrA mutation among clinical isolates of Campylobacter jejuni isolated in Egypt by MAMA-PCR. J. Infect. Dev. Ctries. 4, 9:546-54.

Salem, SF, Mohsen, A, 1997: Brucellosis in fish. Vet. Med. (Praha) 142, 1:5-7.

Samaha, H, Mohamed, TR, Khoudair, R M, Ashour, HM, 2009: Sero-diagnosis of brucello- sis in cattle and humans in Egypt. Immunobiol. 214, 3:223-6.

Shaapan, RM, Ghazy, AA, 2007: Isolation of Toxoplasma gondii from horse meat in Egypt. Pak. J. Biol. Sci. 10, 1:174-7.

Shatla, HM, el-Hodhod, MT, Mohsen, D M, Salah el-Din, MY, 2004: Potential diagnosis of Giardia lamblia infection through specific antibody detection in saliva. J. Egypt. Soc. Parasitol. 34, 2:621-30.

Shoukry, NM, Morsy, TA, 2011: Arthropod borne diseases at Toshka, Upper Egypt. World J. Zool. 6, 2:126-33.

Soliman, A, Mohareb, E, Salman, D, Sa-ad, M, Salama, S, et al, 2010: Studies on West Nile virus infection in Egypt. J. Infect. Publ. Hlth. 3, 2:54-9.

Stasi, MF, Amati, D, Costa, C, et al, 2004: Pettherapy: a trial for institutionalized frail elderly patients. Arch. Gerontol. Geriatr. 9: S407-12.

Steinmuller, N, Demma, L, Bender, JB, et al, 20065: Outbreaks of enteric disease associated with animal contact: not just a foodborne problem anymore. Clin. Infect. Dis. 43:1596-604.

Traub, R, Wade, S, Read, C, et al, 2005: Molecular characterization of potentially zoonotic isolates of Giardia duodenalis in horses. Vet. Parasitol. 130:317-24.

Turell, MJ, Sardelis, MR, Dohm, DJ, O'Guinn, ML, 2001: Potential North American vectors of West Nile virus. Ann. N Y Acad. Sci. 951:317-20.

Turell, MJ, Morrill, JC, Rossi, CA, Gad, AM, Cope, SE, et al, 2002: Isolation of west Nile and Sindbis viruses from mosquitoes collected in the Nile Valley of Egypt during an outbreak of Rift Valley fever. J. Med. Entomol. 39, 1:248-50.

Ward, MP, Brady, TH, Couetil, LL, et al, 2005: Investigation and control of an outbreak of salmonellosis caused by multidrug-resistant Salmonella typhimurium in a population of hospitalized horses. Vet. Microbiol.107:233-9.

Warny, M, Vaerman, JP, Avesani, V, DeImee, M, 1994: Human antibody response to Clostridium difficile toxin A in relation to clinical course of infection. Infect. Immun. 62:38490 .

Weese, JS, McCarthy, L, Mossop, M, et al, 2007: Observation of practices at petting zoos and the potential impact on zoonotic disease transmission. Clin. Infect. Dis. 45: 10-20. 
WHO, 2005: WHO expert consultation on rabies: WHO Tech Rep Ser. Abstract 931.

Wilson, ME, 1991: A World Guide to Infections: Diseases, Distribution, Diagnosis. New York, Oxford University Press.

Youssef, FG, Adib, I, Riddle, MS, Schlett, CD, 2008: A review of cryptosporidiosis in Egypt. J. Egypt. Soc. Parasitol. 38, 1:9-28.
Zborowsky, T, Hellmich, LB, 2011: Impa-ct of place on people and process: the integration of research on the built environment in the planning and design of critical care areas. Crit. Care Nurs. Q. 34, 4:268-81. 